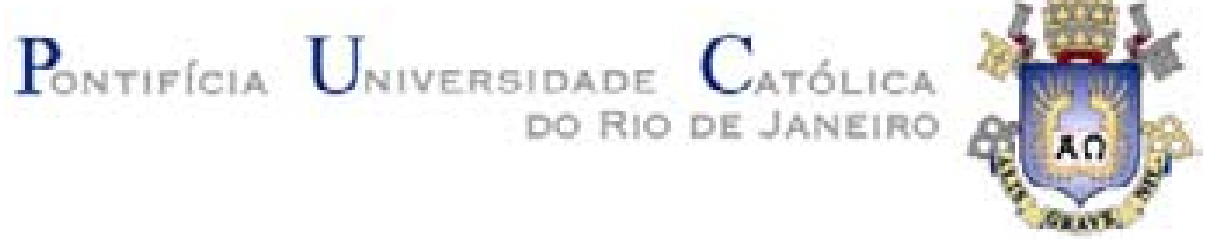

Elias Dias Lopes Filho

Terceira Idade: Perfil de uso do cartão de crédito

Dissertação de Mestrado

Dissertação apresentada ao Programa de Pósgraduação em Administração de Empresas da PUCRio como requisito parcial para obtenção do título de Mestre em Administração de Empresas.

Orientadora: Prof ${ }^{\mathrm{a}}$. Hélène Bertrand 


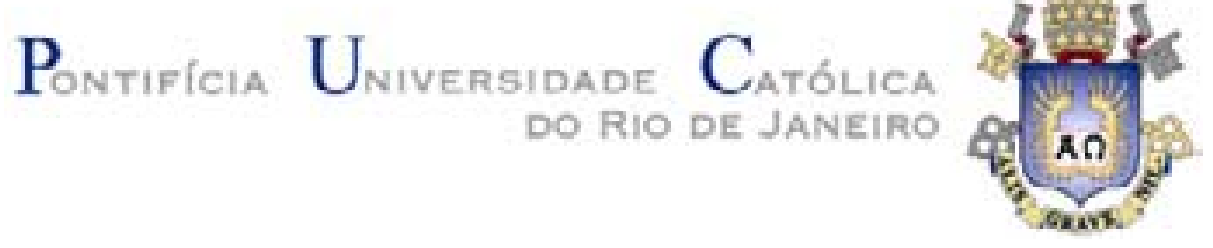

Elias Dias Lopes Filho

\title{
Terceira Idade: Perfil de uso do cartão de crédito
}

\begin{abstract}
Dissertação apresentada como requisito parcial para obtenção do grau de Mestre pelo Programa de Pósgraduação em Administração de Empresas da PUC-Rio. Aprovada pela Comissão Examinadora abaixo assinada.
\end{abstract}

\author{
Prof $^{a}$. Hélène Bertrand \\ Orientadora \\ Departamento de Administração - PUC-Rio
}

Prof. Paulo Cesar de Mendonça Motta Departamento de Administração - PUC-Rio

Prof ${ }^{a}$. Mônica Zaidan Gomes Rossi FACC - UFRJ

Prof. João Pontes Nogueira Vice-Decano de Pós-Graduação do CCS

Rio de Janeiro, 08 de agosto de 2006 
Todos os direitos reservados. É proibida a reprodução total ou parcial do trabalho sem autorização da universidade, do autor e do orientador.

\section{Elias Dias Lopes Filho}

Graduou-se em Administração de Empresas na PUC-Rio (Pontifícia Universidade Católica do Rio de Janeiro) em 2003. No âmbito profissional, atuou na Redecard nas áreas de Business Intelligence e Comercial. Atualmente trabalha na AmBev na área de vendas.

Ficha Catalográfica

Lopes Filho, Elias Dias

Terceira Idade : Perfil de uso do cartão de crédito / Elias Dias Lopes Filho ; orientadora: Hélène Bertrand. - Rio de Janeiro : PUC, Departamento de Administração, 2006.

97 f. : il. ; $30 \mathrm{~cm}$

Dissertação (mestrado) - Pontifícia Universidade Católica do Rio de Janeiro, Departamento de Administração.

Inclui referências bibliográficas.

1. Administração - Teses. 2. Terceira Idade. 3. Cartão de Crédito. 4. Comportamento de uso. I. Bertrand, Hélène. II. Pontifícia Universidade Católica do Rio de Janeiro. Departamento de Administração. III. Título. 


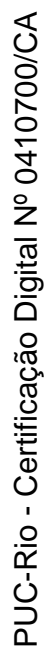

Aos meus pais e irmãos por todo apoio, paciência e incentivo em todos os momentos. 


\section{Agradecimentos}

A minha orientadora, Professora Hélène Bertrand, pela atenção, apoio e ajuda na realização deste trabalho.

A todos os professores, que contribuíram e se dedicaram para minha formação com ensinamentos preciosos.

A todos os funcionários do Departamento, pela presteza e atenção demonstrada.

Aos colegas que fiz ao longo desta jornada, pela colaboração e apoio.

A todas as pessoas, que foram entrevistadas e que ajudaram na distribuição e preenchimento do questionário.

Aos meus pais e irmãos por terem estado sempre ao meu lado.

A minha tia Iraid e minha avó Irene, pela força e carinho.

A todos os meus amigos e familiares que sempre me apoiaram. 


\section{Resumo}

Lopes Filho, Elias Dias; Bertrand, Hélène. Terceira Idade: Perfil de uso do cartão de crédito. Rio de Janeiro, 2006. 97p. Dissertação de Mestrado Departamento de Administração, Pontifícia Universidade Católica do Rio de Janeiro.

O aumento da expectativa de vida dos brasileiros é cada vez maior e, conseqüentemente, também sua presença na economia. Assim como o público idoso, o mercado de cartões de crédito também cresce em ritmo acelerado. Este trabalho estuda as características do portador de cartão de crédito do segmento da Terceira Idade, ou melhor, pessoas com mais de 60 anos, assim como seu comportamento em relação ao uso do cartão de crédito. Aplicou-se uma pesquisa qualitativa, através de entrevistas em profundidade, que levou à análise de outras faixas etárias para fins de comparação do comportamento de uso do cartão de crédito, assim como a aplicação de um questionário no aspecto quantitativo. Os resultados apontaram para características conservadoras por parte da Terceira Idade no que se refere ao uso do cartão de crédito.

\section{Palavras-chave}

Terceira Idade; Cartão de Crédito; Comportamento de Uso. 


\section{Abstract}

Lopes Filho, Elias Dias; Bertrand, Hélène. Third Age: Credit card use profile. Rio de Janeiro, 2006. 97p. MSc. Dissertation - Departamento de Administração, Pontifícia Universidade Católica do Rio de Janeiro.

The increase of life expectation of the Brazilians grows bigger and bigger and, consequently, also their presence in the country's economy. Just as the aged public, the credit card market also grows in an accelerated rhythm. This work studies the characteristics of the Third Age credit card bearer segment, in other words, people over the sixties, as well as their behavior regarding the credit card use. A qualitative research was applied, by means of in-depth interviews, which lead to the analysis of other age groups aiming at the comparison of the credit card use behavior, as well as the application of a quantitative wise questionnaire. The results point towards conservative characteristics on the part of the Third Age as far as the credit card use is concerned.

\section{Keywords}

Third Age; Credit Card; Use Behavior. 


\section{Sumário}

1 Introdução 12

1.1. Contextualização 14

1.2. Problema 16

1.3. Objetivos 17

1.4. Relevância do Estudo 18

$\begin{array}{ll}\text { 1.5. Delimitação do Estudo } & 19\end{array}$

2 Revisão de Literatura $\quad 20$

2.1. O Aumento da Expectativa de Vida dos Brasileiros 20

2.1.1. Curiosidades 23

2.2. Sociedade de Consumo e sua Importância para a Economia 25

2.2.1. O Comportamento do Consumidor 28

2.2.2. O Processo de Compra 32

2.3. Segmentação de Mercado 34

2.4. Comportamento e Satisfação do Consumidor da Terceira Idade 36

2.5. A Nova Imagem da Terceira Idade na Economia 39

2.6. A Terceira Idade e o Mercado de Cartões de Crédito 41

2.6.1. Cartão de Crédito - Origem 42

2.6.2. Agentes do Mercado de Cartões de Crédito 44

2.6.3. Novidades de Cartões de Crédito e Estímulo de Uso 46

3 Metodologia $\quad 48$

3.1. Introdução 48

3.2. Tipo de Pesquisa $\quad 49$

3.3. Universo e Amostra 52

3.4. Coleta de Dados 53

3.4.1. Entrevistas em Profundidade 53

3.4.2. Questionário $\quad 54$

3.5. Tratamento dos Dados 56

3.6. Limitações do Método 57 
4 Resultados $\quad 58$

4.1. Entrevistas em Profundidade 58

4.2. Questionário 61

5 Conclusão $\quad 86$

5.1. Considerações Finais 86

5.2. Sugestões/Recomendações para Estudos Futuros 88

6 Referências bibliográficas $\quad 89$

7 Anexos $\quad 94$

7.1. Questionário 94 


\section{Lista de Gráficos}

$\begin{array}{ll}\text { Gráfico } 1 \text { - Distribuição \% por sexo } & 61\end{array}$

Gráfico 2 - Distribuição \% por sexo e faixa etária 62

Gráfico 3 - Distribuição \% por faixa etária 62

Gráfico 4 - Distribuição \% por residência 63

Gráfico 5 - Distribuição \% por residência e faixa etária 63

Gráfico 6 - Distribuição \% com quem reside $\quad 64$

Gráfico 7 - Distribuição \% com quem reside por faixa etária 64

Gráfico 8 - Distribuição \% por ocupação 65

Gráfico 9 - Distribuição \% por ocupação e faixa etária 66

Gráfico 10 - Distribuição \% por quantidade de cartões 66

Gráfico 11 - Distribuição \% por quantidade de cartões e faixa etária 67

Gráfico 12 - Distribuição \% por bandeira 68

Gráfico 13 - Distribuição \% por bandeira e faixa etária 68

Gráfico 14 - Distribuição \% de cartões últimos 10 anos 69

Gráfico 15 - Distribuição \% de cartões últimos 10 anos por faixa etária 70

Gráfico 16 - Pessoas com cartões de outro banco 70

Gráfico 17 - Pessoas com cartões de outro banco por faixa etária 71

Gráfico 18 - Distribuição \% por renda mensal 72

Gráfico 19 - Distribuição \% por renda mensal e faixa etária 72

Gráfico 20 - Distribuição \% por gasto médio 73

Gráfico 21 - Distribuição \% por gasto médio e faixa etária 74

Gráfico 22 - Preferência por meio de pagamento 75

Gráfico 23 - Preferência por meio de pagamento por faixa etária 75

Gráfico 24 - Pagaria tudo no cartão de crédito 76

Gráfico 25 - Pagaria tudo no cartão de crédito por faixa etária 77 


\section{Lista de Tabelas}

Tabela 1 - Freqüência \% atributo Valor da Anuidade 78

Tabela 2 - Freqüência \% atributo Facilidade/ Praticidade 78

Tabela 3 - Freqüência \% atributo Segurança 78

Tabela 4 - Freqüência \% atributo Agilidade/ Rapidez 79

Tabela 5 - Freqüência \% atributo Programa de Milhagem 79

Tabela 6 - Freqüência \% atributo Aceitação Pontos de Venda 79

Tabela 7 - Freqüência \% atributo Bandeira 79

Tabela 8 - Freqüência \% atributo Programa de Pontos 80

Tabela 9 - Freqüência \% atributo Limite de Crédito 80

Tabela 10 - Freqüência \% atributo Parcelado Sem Juros 80

Tabela 11 - Freqüência \% atributo Parcelado Com Juros 80

Tabela 12 - Freqüência \% atributo Aceitação no Exterior 81

Tabela 13 - Freqüência \% atributo Serviços de Internet 81

Tabela 14 - Freqüência \% atributo Saques de Emergência 81

Tabela 15 - Freqüência \% atributo Cartões com Chip 81

Tabela 16 - Freqüência \% atributo Centralizar Pagamentos 82

Tabela 17 - Freqüência \% atributo Status Cartão 82

Tabela 18 - Freqüência \% atributo Débito Automático 82

Tabela 19 - Freqüência \% atributo Cartão Múltiplo 82

Tabela 20 - Freqüência \% atributo Taxa de Juros 83

Tabela 21 - Freqüência \% atributo Acesso Área Vip Aeroportos 83

Tabela 22 - Freqüência \% atributo Seguro Viagem 83

Tabela 23 - Freqüência \% atributo Seguro Veículos Alugados Exterior 83

Tabela 24 - Freqüência \% atributo Seguro Bagagem 84

Tabela 25 - Freqüência \% atributo Serviços Hospitalares no Exterior 84

Tabela 26 - Freqüência \% atributo Seguro Perda ou Roubo do Cartão 84

Tabela 27 - Freqüência \% importância atributos - Terceira Idade 85 